\section{Simple reaction time, statistical decision theory, and the speed-slowness tradeoff}

\author{
LESLIE HENDERSON \\ University of Guelph, Guelph, Ontario, Canada
}

Simple auditory RT was measured at three stimulus intensities under both speed and accuracy instructions. The slope of RT over intensity was greater for accuracy criteria, as predicted by statistical decision theory. Speed criterion performance was not attributable to a shift in preprogrammed anticipatory responses.

Several authors have recently proposed statistical decision models of choice reaction time (reviewed in Smith, 1968). As Swensson \& Edwards (1970) have pointed out, the predictions of such models invariably apply to the speed-accuracy tradeoff. Simple RT, which is normally designed as an error-free task, has, therefore, been treatable only by implication from the more complex case.

Statistical decision models of simple RT have restricted their attention to the effects of stimulus intensity and their interaction with criterion placement (John, 1967; Grice, 1968). In particular, they have explained the well-known difference in results between randomized and blocked stimulus intensities as due to the necessity of a single criterion and, therefore, large intensity effect in the former case, whereas, in the latter case, the criterion may vary according to the signal intensity in such a way as to attenuate the intensity effect. A corollary of the model is that increases in the criterion value (caution) will result in a relatively greater lengthening of RT to weak stimuli. In support of this prediction, John (1967) cites studies which show this relative slowing when the signal probability is reduced, an operation which decision theory assumes will raise criterion if the pay offs remain constant.

The present study aims to test this prediction more simply and directly by attempting to manipulate criterion by instructions. By employing a less-than-unity signal probability, it was hoped to give some empirical meaning to "accuracy" instructions and to create the opportunity for measurable false positives. METHOD

A red neon light on the response console initiated a trial by delivering a warning signal of $.5 \mathrm{sec}$ duration. After a delay of $1.0,1.5$, or $2.0 \mathrm{sec}$, a burst of white noise was delivered binaurally through headphones at 40,60 , or $90 \mathrm{~dB}$ SPL, measured at the earphones. Signal intensities and warning intervals were randomized, with the constraint that each warning interval occur an equal number of times at each intensity. The onset of the white noise started a Hunter millisecond stop clock, which was stopped by the S's response of depressing a telegraph key. The response also terminated the white-noise signal and initiated a 5-sec intertrial interval. Signal probability was .75 and was known to the $\mathrm{S}$. That is, on $25 \%$ of the trials, no signal followed the warning light. After a delay of $7 \mathrm{sec}$, the retum of the warning light heralded a new trial.

A block of trials consisted of 72 trials. For each $\mathrm{S}$ four blocks were run with speed and accuracy conditions in an ABBA sequence, beginning with accuracy for half the Ss. Prior to this, a practice session of 20 trials at each intensity was given. The speed instructions urged the $S$ to react as quickly as possible; he was told that a few responses on catch trials would be permissible and was given immediate feedback on his latency. The accuracy instructions were to react only as fast as was consistent with the avoidance of all catch-trial responses or anticipatory responses. No feedback on latency was given. These conditions were described to the S as "risky" and "cautious," respectively.

The Ss were six male psychology undergraduate volunteers with normal hearing.

\section{RESULTS AND DISCUSSION}

Individual and group mean median RTs are shown in Table 1 for each stimulus intensity, grouped by instructed criterion and block of trials. For all $S s$ and conditions, latencies vary inversely with stimulus intensity, as is predicted trivially by decision theory for the case of randomized intensities. The ability of the Ss to vary their criteria according to instructions and the presence of feedback is evident from the marked difference in RTs. However, two Ss for whom the final block was under accuracy instructions (S 5 and $S 6$ ) reported a difficulty in returning to a high criterion. As can be seen, their
RTs for the second accuracy block differ little from the speed conditions.

For all Ss in each block, the slope of RT as a function of stimulus intensity is steeper for the accuracy (high criterion) conditions, as predicted by the statistical decision model. This interaction is plotted in Fig. 1, which displays the group mean median RTs for each condition. The manipulation of criterion in the present experiment is, therefore, consistent in its effect with manipulations involving the a priori probability of the signal (Thrane, 1962), though the relative contribution of instructions and feedback cannot be assessed. As can be seen from Fig. 1, the low criterion changes vary little from block to block, whereas the high criterion drops substantially from the first to the second block of trials. While this drop is disproportionately weighted by the performance of $\mathrm{S} 3$, it is suggested that, in terms of the instructions used, an accuracy criterion is subject to greater outcome learning. Such learning constitutes a particular case of Grice's (1968) hypothesis that the effect of practice upon RT is a progressive lowering of the criterion.

For each $S$ a product-moment correlation was calculated between the mean and standard deviation of RT for Three Intensities by Two Blocks by Two Instructions. The high positive correlation first discovered by Chocolle (1945) was obtained. For $S s$ 1-6, respectively, $r=.43$, $.84, .85, .95, .93$, and .84 . Since most of

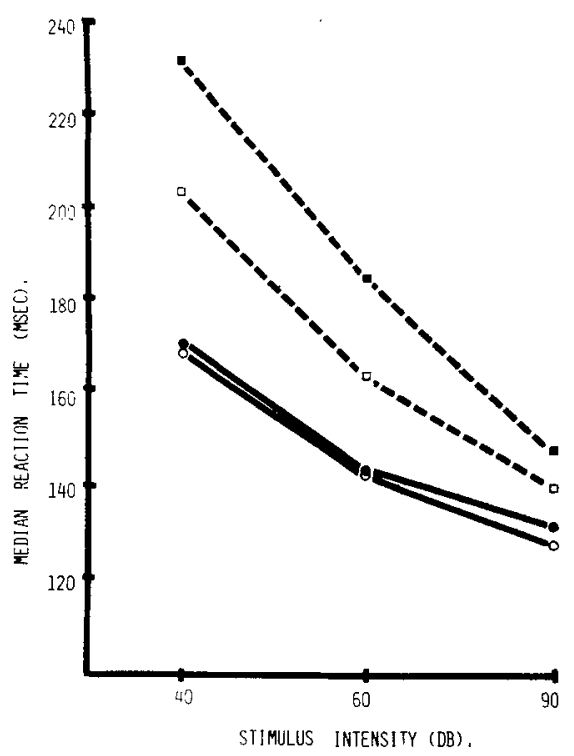

Fig. 1. The group mean of median RTs as a function of stimulus intensity. Filled and open squares represent first and second blocks, respectively, under accuracy instructions. Filled and open circles represent first and second blocks under speed instructions. 
Table 1

Median RT as a Function of Stimulus Intensity, Instructions, and Block of Trials

\begin{tabular}{|c|c|c|c|c|c|c|c|}
\hline & \multirow[b]{2}{*}{ Block } & \multicolumn{3}{|c|}{ Accuracy Criterion } & \multicolumn{3}{|c|}{ Speed Criterion } \\
\hline & & $40 \mathrm{~dB}$ & $60 \mathrm{~dB}$ & $90 \mathrm{~dB}$ & $40 \mathrm{~dB}$ & $60 \mathrm{~dB}$ & $90 \mathrm{~dB}$ \\
\hline S 1 & $\begin{array}{l}1 \\
2\end{array}$ & $\begin{array}{l}183 \\
222\end{array}$ & $\begin{array}{l}154 \\
164\end{array}$ & $\begin{array}{l}136 \\
144\end{array}$ & $\begin{array}{l}138 \\
141\end{array}$ & $\begin{array}{l}127 \\
122\end{array}$ & $\begin{array}{l}121 \\
117\end{array}$ \\
\hline S 2 & $\begin{array}{l}1 \\
2\end{array}$ & $\begin{array}{l}243 \\
213\end{array}$ & $\begin{array}{l}176 \\
192\end{array}$ & $\begin{array}{l}149 \\
145\end{array}$ & $\begin{array}{l}179 \\
180\end{array}$ & $\begin{array}{l}150 \\
146\end{array}$ & $\begin{array}{l}131 \\
124\end{array}$ \\
\hline S 3 & $\begin{array}{l}1 \\
2\end{array}$ & $\begin{array}{l}439 \\
284\end{array}$ & $\begin{array}{l}363 \\
216\end{array}$ & $\begin{array}{l}236 \\
194\end{array}$ & $\begin{array}{l}248 \\
232\end{array}$ & $\begin{array}{l}200 \\
193\end{array}$ & $\begin{array}{l}184 \\
178\end{array}$ \\
\hline S 4 & $\begin{array}{l}1 \\
2\end{array}$ & $\begin{array}{l}177 \\
175\end{array}$ & $\begin{array}{l}139 \\
138\end{array}$ & $\begin{array}{l}126 \\
123\end{array}$ & $\begin{array}{l}151 \\
159\end{array}$ & $\begin{array}{l}126 \\
136\end{array}$ & $\begin{array}{l}116 \\
118\end{array}$ \\
\hline S 5 & $\begin{array}{l}1 \\
2\end{array}$ & $\begin{array}{l}192 \\
184\end{array}$ & $\begin{array}{l}142 \\
139\end{array}$ & $\begin{array}{l}119 \\
119\end{array}$ & $\begin{array}{l}170 \\
163\end{array}$ & $\begin{array}{l}134 \\
132\end{array}$ & $\begin{array}{l}121 \\
117\end{array}$ \\
\hline S 6 & $\begin{array}{l}1 \\
2\end{array}$ & $\begin{array}{l}153 \\
138\end{array}$ & $\begin{array}{l}130 \\
127\end{array}$ & $\begin{array}{l}116 \\
107\end{array}$ & $\begin{array}{l}133 \\
133\end{array}$ & $\begin{array}{l}118 \\
127\end{array}$ & $\begin{array}{l}113 \\
109\end{array}$ \\
\hline$\overline{\mathrm{X}}$ & $\begin{array}{l}1 \\
2 \\
\end{array}$ & $\begin{array}{l}231 \\
203 \\
\end{array}$ & $\begin{array}{l}184 \\
163 \\
\end{array}$ & $\begin{array}{l}131 \\
139 \\
\end{array}$ & $\begin{array}{l}170 \\
168 \\
\end{array}$ & $\begin{array}{l}143 \\
142\end{array}$ & $\begin{array}{l}131 \\
127\end{array}$ \\
\hline
\end{tabular}

the variance in these correlations is for a tradeoff. However, it is possible that accounted for by the large intensity effect, the error component of simple RT consists the variance of RT was compared for the in anticipation responses. Snodgrass et al two criteria across Ss and intensities. A sign (1967) have shown that Ss may base test revealed that the increase in variability responses on time estimates of the of RT from risky to cautious criteria was foreperiod in simple RT when there are not significant at $\mathrm{p}<.10$. This is in accordance with the predictions of the variable-input model of McGill (1963) and the variable-criterion model of Grice (1968), that RT variability is linearily related to signal intensity but unrelated to criterion changes.

A major problem for the statistical decision model is the nature of the criterion process. Swensson \& Edwards $(1970)$, in a series of choice-RT experiments, failed to find the continuous speed-accuracy tradeoff predicted by random walk models with variable cost for time. Instead, their Ss either responded accurately and accepted the time cost or made a preprogrammed detection response and accepted chance-level error rates. False positives in the present task were negligible. Out of 72 possible responses on catch trials, one $S$ made 2 and another made 1 , the rest being error-free. While these errors all occurred in the second speed block. they provide scant evidence high costs for time, and Snodgrass (1969) has advanced a two-strategy model of the tradeoff process in terms of anticipatory and detection responses. This is analogous to the discontinuous tradeoff model employed by Swensson \& Edwards (1970) for choice RT.

There is no evidence for such a process underlying the criterion shift in the present experiment. The choice of only three foreperiods, with a range which is large with respect to that of RT, should render such a strategy obvious in terms of RTs clearly below the accepted irreducible minimum and an exaggeration of the increased variability noted by Snodgrass (1969) for time-estimation responses. In fact, the difference in variability was insignificant and in the opposite direction. Furthermore, taking the conventional, if arbitrary, 100-msec estimate of the irreducible minimum RT, only two Ss ever produced RTs faster than this, accounting for $5.5 \%$ and $0.5 \%$ of their responses.

\section{ERRATUM}

DERVIN, DENNIS, \& DEFFENBACHER, KENNETH. Effects of proportion of positive instances and degree of restriction on the induction of a princi

the induction of a principle. Psychon. Sci., 1970, 21 (2), 79-80.-P. 80, Col. 2. The last sentences of the first paragraph should read as follows: "An analysis involving Groups U, RN50, RL50, and RNL50 yielded $H(3)=16.02, p<.01$. Analysis of Groups U, RN70, RL70, and RNL70 produced $H(3)=6.58, p<.10$. Finally, analysis of Groups. RN50, RL50, RNL50. RN70, RL70, and RNL70 yielded $\mathrm{H}(5)=$ $22.0, \mathrm{p}<.001$."
In these data, therefore, there is little evidence for speed being gained at the cost of errors, of whatever type. Errors, within the performance limits investigated. are neither a necessary part of the strategy for gaining speed nor a component of the payoff costs. However, maximization of the reward for speed may be constrained by the implicit cost of effort.

In conclusion, the present experiment finds qualitative support for a statistical decision model of simple RT: Ss adopted criteria yielding different latencies. While the error rate was negligible, the slope of RT over signal intensity provided an estimate of criterion location. This relationship may provide a quantitative basis for further applications of decision models to simple RT.

\section{REFERENCES}

CHOCOLLE, R. Variations des temps de reaction auditif en fonction de l'intensité à divers frequences. Année Psychologique, 1945, 41-42, 65-124.

GRICE, G. R. Stimulus intensity and response evocation. Psychological Review. 1968, 75. 359-373.

JOHN, I. D. A statistical decision theory of simple reaction time. Australian Journal of Psychology, 1967, 19, 27-34.

McGILL, W. J. Stochastic latency mechanisms. In R. D. Luce, R. R. Bush, and E. Galanter (Eds.) Handbook of mathematical psychology. Vol. 1. New York: Wiley, 1963. Pp. 309-360.

SMITH, E. E. Choice reaction time: An analysis of the major theoretical positions. Psychological Bulletin, 1968.69,77-110.

SNODGRASS, J. G. Foreperiod effects in simple reaction time: Anticipation or expectancy. Journal of Experimental Psychology, 1969 79, 1-19.

SNODGRASS, J, G., LUCE, R. D., \& GALANTER, E. Some experiments on simple and choice reaction time. Journal of Experimental Psychology, 1967, 75, 1-17.

SWENSSON, R. G., \& EDWARDS, W. Response strategies in a two-choice reaction task with a linear cost for time. Unpublished manuscript, 1970.

THRANE, V. C. Sensory and preparatory factors in response latency. V. Stimulus blanks as regulator of preparatory set. Scandinavian Journal of Psychology, 1962, 3, 1-15. 